\title{
Yeni Tıp Teknolojilerinin Kullanımı ve Etik
}

\author{
New Medical Technologies and Ethical Issues
}

\author{
Osman Hayran \\ Istanbul Medipol Üniversitesi Tip Fakültesi \\ Yazışma Adresi / Correspondence: \\ Osman Hayran \\ İstanbul Medipol Üniversitesi Tip Fakültesi \\ T: +90532 $2634321 \quad$ E-mail: ohayran@gmail.com \\ Orcid \\ Osman Hayran: https://orcid.org/0000-0002-9994-5033
}

Geliş Tarihi / Received : 13-03-2019 Kabul Tarihi / Accepted : 28-04-2019 Yayın Tarihi / Online Published: 29-08-2019

Hayran O., Yeni Tip Teknolojilerinin Kullanımı ve Etik,

J Biotechnol and Strategic Health Res. 2019;3(2):54-60 DOİ: bshr.539032

Özet

Nanoteknolojiler, bilişim teknolojileri, genetik teknoloji, sentetik biyoloji, rejeneratif tıp, robotik uygulamalar, nöroteknoloji ve yapay zeka son yıllarda hızlı gelişen ve tıbbi uygulamalara yenilikler getiren teknolojilerden bazılarıdır. Bunlar sayesinde pek çok sağlık sorununa daha kolay tanı koymak ve daha iyi tedavi etmek mümkün hale gelmiștir. Yeni tıp teknolojilerinin asıl amacı hastalıkların tanı ve tedavisini sağlamak olsa da aynı teknolojiler sayesinde daha güçlü, daha sağlıklı, daha uzun yaşama olasılı̆̆ı olan insan haline gelme olanağı da sağlanmış olmaktadır. Bu durum gelişen teknolojilerin hızla kullanıma girmelerine, amacına uygun olmayan şekilde tüketilmelerine ve pek çok etik soruna yol açabilmektedir. Ortaya çıkabilen etik sorunlar üç ana başlık altında toplanmaktadır: Hasta güvenliği sorunları, kaynakların adil kullanımı sorunları ve norm değișikliği sorunları. Yeni teknolojilerin özellikle ilk kullanım dönemlerinde kullanıcların beceri eksikliğine bağlı olarak ölümlere kadar gidebilen önemli komplikasyonlar görülebilmektedir. Yeni teknolojilerin kullanımı konusunda toplumun varlıklı ve güçlü kesimleri daha ayrıcalıklı olduğundan hakkaniyetli bir paylaşım söz konusu olmamakta, bu da yeni insani sorunlara yol açabilmektedir. Bazı yeni teknolojiler ise hastalık tedavisi dışında daha güzel ve daha genç görünmek, daha keskin bir hafizaya sahip olmak, fit olmak gibi tıp dışı nedenlerle kullanılabildiğinden bireysel normları değiştirmekte ve hizmet sunanlar üzerinde bu doğrultuda bir toplumsa baskıya neden olmaktadır. Öte yandan bu teknolojilerin gelișmesinin ve yaygın kullanımının iyi ve gerekli olduğunu savunan görüșler de bulunmaktadır. Söz konusu etik sorunların hiç birisi teknolojinin kendisi ile ilgili olmayıp, onu kullananların bilgi, tutum ve becerilerinden kaynaklanmaktadır. Bu durum tıp eğitiminde ve uygulamalarında etik konulara daha fazla yer verilmesinin önemini göstermektedir.

Anahtar Tip teknolojisi, Etik sorunlar, Hasta güvenliği, Hakkaniyet

Nanotechnologies, information technologies, genetic technology, synthetic biology, regenerative medicine, robotic applications, neurotechnology and artificial intelligence are some of the technologies that are developing rapidly in recent years and bring innovations to medical applications. New medical technologies enable us better diagnose and better treat many health problems. Although the main purpose of new medical technologies is to provide diagnosis and treatment of diseases, the same technologies enable us to become stronger, to live healthier and longer. This situation can lead to rapid and frequent use of developing technologies beyond purpose and may cause many ethical problems. Ethical problems that may arise are grouped under three main headings: Patient safety issues, unfair use of resources and problems of norm change. Significant complications can be seen, especially in the initial use periods of new technologies due to lack of skills of users. As the wealthy and powerful segments of the society are more privileged in the use of new technologies, there is no equitable sharing, which can lead to new humanitarian problems. Some new technologies change the individual norms and cause social pressure on the service providers, because they can be used for non-medical reasons such as looking more beautiful and younger, having a sharper memory and being fit. However, none of these ethical problems are related to the technology itself, but the knowledge, attitude and skills of those who use it. This demonstrates the importance of more ethical issues in medical education and practice. 


\section{Giriş}

Teknolojik gelişmelerin hızlanmış olması sağlık alanında önemli değişikliklere yol açmakta, geleneksel olarak insani ilişki yönü ağır basan tıbbi uygulamalar şekil değiştirmektedir. Bu değişim ve dönüşüm pek çok konuda hayatı kolaylaştırıp sayısız yararlar sağlamanın yanı sıra yeni soru ve sorunları da gündeme getirmektedir. Yapay zeka ve akıllı cihazlar nedeniyle hekimlik mesleğinin devre dışı kalması söz konusu olabilir mi? Teknolojik gelişmelerin insan bedenine uygulanmasının sinırları ne olmalı? Geleceğin hastaneleri, sağlık kuruluşları nasıl olacak? Daha da önemlisi, yeni teknolojiler güvenli mi, getireceği sorunlar neler olabilir? Bunlar akla hemen geliveren sorulardan bazılarıdır. Gerekçesi ne olursa olsun bilimsel ve teknolojik gelişmelerin engellenmesi söz konusu olmayacağına göre yapılması gereken en akıllıca işin gelecekte olacakları öngörmek ve ona göre pozisyon almak olduğu ortadadır. Özü itibarıyla anaerkil bir yapıya sahip olan hekimlik, sanayi devrimi ile birlikte erkek egemen bir yapıya dönüşmüştür. $\mathrm{Bu}$ dönemdeki bilimsel gelişmeler tıpta Kartezyen yaklaşımın gelişmesine neden olmuştur. İnsan vücudunu bir makine gibi düşünmek, birbiri ile bağlantılı olan çeşitli organ ve sistemlerin çalışma biçimini inceleyerek ortaya çıkan bozuklukların kaynağını anlamak ve tamir etmek sanayi devrimi sonrası tıp anlayışının dayandığı paradigmadır. Índirgemeci bir mantık ile deterministik bir nedensellik anlayışına dayanan bu yaklaşım sayesinde bazı başarılar elde edilmiş, bulaşıcı hastalıklarla mücadele konusunda önemli gelişmeler sağlanmış, ancak, özellikle kronik hastalıklar konusunda yeterince yol kat etmek mümkün olmamıştır.

Günümüzde bilişim alanındaki gelişmeler yeni bir anlayışı gündeme getirmektedir. Veri, kodlama, enformasyon ve bilgi kavramlarının her alanda kullanılıyor olması, veri yükleme ve indirme işlemlerinin günlük hayatın parçası haline gelmesi, eski paradigmayı değişime zorlamaktadır. İnsan vücuduna makine muamelesi yapmak yerine, akıllı cihaz muamelesi yapmak, patolojileri kötü kodlamalar, kötü yazılımlar gibi görerek düzeltmeye çalışmak daha yaygın bir anlayış haline gelmektedir. Kök hücre, genetik ve sentetik biyoloji alanındaki gelişmelerle bozulmuş dokuları, eskimiş organları yenilemek; nanoteknolojinin sağladığı imkanlarla hücre düzeyinde müdahaleler yapmak, kötü yazılımları düzeltmek mümkün olabilmektedir. Kuantum mekaniği, kaos teorileri, sistem teorileri ve karmaşıklık bilimindeki gelişmeler nedensellik anlayışımızı da değiştirmeye başlamıştır. Günümüzde başlıca ölüm nedeni olan kanser, kalp damar hastalıkları, metabolik bozukluklar gibi sorunların basit neden-sonuç ilişkileri ile açıklanamayacağı, çok nedenli, çok değişkenli, karmaşıklık ilkelerine dayanan bir nedensellik yaklaşımına ihtiyaç olduğu görülmektedir. Örneğin, akciğer kanserinin tütün kullanımından; metabolik sendrom, obezite, Tip II diyabetin yüksek fruktozlu misır şurubu tüketiminden; diyabet ve depresyon ikilisinin izolasyon ve istismardan bağımsız düşünülemeyeceği artık gayet iyi bilinmektedir. Hatta viral bir hastalık olan AIDS'in bile çevresel pek çok değişkenle yakın ilişkisi olan bir sindemi olduğu tartışılmaktadır.

Nedensellik konusundaki paradigma değişikliği büyük ölçüde gelişen yeni teknolojilerin sayesinde olmaktadır. Yani yeni tıp teknolojileri sayesinde bir yandan insan bedenini daha iyi tanıyıp sağlık sorunlarımıza daha doğru çözümler üretirken bir yandan da nedensellik konusundaki anlayışımız değişmektedir. Bunlar iyi gelişmelerdir. Ancak, aynı teknolojilerin yeni sorunlara neden olması da kaçınılmazdır. Bu sorunlara geçmeden önce tıp teknolojisi kavramına açılılı getirmek gerekir.

Türk Dil Kurumu (TDK) tanımına göre teknoloji, “insanın maddi çevresini denetlemek ve değiştirmek amacıyla geliştirdiği araç gereçlerle bunlara ilişkin bilgilerin tümü” demektir ${ }^{1}$. Sağlık teknolojisi ise Dünya Sağlık Örgütü tarafından, "bir sağlık sorununu çözmek ve yaşam kalitesini geliştirmek amacıyla geliştirilen organize bilgi ve becerilerin, cihazlar, ilaçlar, aşılar, işlemler ve sistemler şeklindeki her türlü uygulaması" şeklinde tanımlanmaktadır ${ }^{2}$. Konumuz olan Tip teknolojisi, "hastalıkların erken 
dönemde tanısı, daha az invasiv yöntemlerle tedavi edilerek hastaneye-rehabilitasyona olan ihtiyacın azaltılması, maliyetlerin düşürülmesi ve yaşam kalitesinin arttırılması amaçlarıyla kullanılan her türlü cihaz, enformasyon teknolojisi, biyo-teknolojiler ve sağlık hizmetleri” anlamına gelmektedir.

$\mathrm{Bu}$ tanımlardan da anlaşılacağı üzere teknoloji sözcüğü ile kastedilen aslında iki farklı şeydir: Birincisi teknolojik paradigma, ikincisi ise teknolojik cihazlar-araçlar ${ }^{3}$. Teknolojik paradigma, teknolojiyi ifade eden kavramlar, teoriler ve yöntemlerdir. Teknolojik cihazlar ise paradigmanın uygulanmış halidir. Örneğin, bir makineyi uçurma kavramı, aerodinamik teoriler, uçmayı kontrol için kanatlardan, yüzeylerden yararlanma yöntemi paradigma; uçak ise bunların cihaza dönüşmüş halidir. Teknolojik gelişme dediğimiz gelişmeler bunların her ikisinde de ayrı ayrı veya aynı anda olabilen gelişmelerdir.

Tıp alanındaki bilgilerin artışına paralel olarak teknolojik gelişmeler de hız kazanmış ve sağlık hizmetleri şekil değiştirmeye başlamıştır. Tarihsel olarak insan ilişkisi ağırlıklı olan tıbbi uygulamalar yerini teknolojik uygulamalara bırakmaya başlamıştır. Özellikle bilişim teknolojilerindeki gelişmeler bir yandan bilgi üretimini arttırmakta diğer yandan da var olan bilginin kullanımını yaygınlaştırmaktadır. Yeni bilgi ve teknolojilere bağlı olarak eski uygulamalarımızın bir kısmı geçerliliğini yitirmektedir. Yapılan hesaplamalara göre tıp bilgilerinin yarılanma ömrü-2-3 yıl kadardır. Bilgilerin artışına ve değişimine paralel olarak teknolojik gelişmeler kabaca iki yol izlemektedir: Ya eski teknolojiler daha da geliştirilmekte yani evrim geçirmektedir, ya da yepyeni teknolojiler gündeme gelmekte ve bunların kullanılması ile birlikte devrim gerçekleşmektedir.

Teknolojik gelişmelerin sosyal hayat üzerinde ciddi etkilere yol açması teknolojik devrim anlamına gelmektedir. Bazen de yeni teknolojiler çok sınırlı olan etkileri ve gelişememe gibi nedenlerle sönük kalabilmektedir (stetoskop, tost makinesi gibi). Hangi teknolojilerin ne kadar zaman sonra nasıl devrim yaratacağını, ne tür sonuçlar ortaya çıkaracağını öngörmek, aynen bir çocuğun büyüdüğünde nasıl olacağının bilinememesi gibi karmaşık, tahmini zor bir konudur.

Yeni tıp teknolojilerinin sağlık hizmeti tüketimine etkisi Epey bir zamandır günlük yaşantımıza girmiş olan ve tıbbi uygulamaları etkileyen önemli teknolojileri şu şekilde sıralamak mümkündür: Nanoteknolojiler, bilişim teknolojileri, genetik teknoloji, sentetik biyoloji, rejeneratif tıp, robotik uygulamalar, nöroteknoloji ve yapay zeka.

Bu yöntemlerle hastalıklara daha erken dönemde ve daha doğru şekilde tanı konulabilmekte, tedaviler de daha başarılı olabilmektedir. Yeni gelişen tıp teknolojileri aslında hasta ve/ya engelli olanların sağlık durumuna katkı sağlama amacını gütmekle birlikte sağlıklı olanları daha güçlü yapma potansiyeline de sahiptir ve bu amaçla kullanımları konusunda hekimler üzerinde yoğun bir baskı söz konusudur. Bu baskının bir kısmı kurumlardan, diğer kısmı ise hastalardan gelmektedir.

Hekimler üzerindeki baskılara ek olarak, “sunucular tarafından kışkırtılan talepler” ve sigortalılardan kaynaklanabilecek "ahlaki tehlikeler" bu teknolojilerin tüketimlerinin aşırı ve gereksiz şekilde artmasına neden olabilmektedir. Özellikle bizim ülkemiz gibi malpraktis yaptırımlarının bulunmadığı ya da zayıf olduğu ülkelerde bu artış, hem sağlık harcamalarını arttırmakta hem de hasta güvenliği açısından çeşitli sorunlara neden olabilmektedir. Bunun örnekleri konusunda toplum olarak ne yazık ki oldukça kötü deneyimlere sahibiz. Tomografinin yaygınlaşmaya başladığı 80 'li yıllarda gerekli gereksiz tomografi kullanımında liderlik, 3. jenerasyon sefalosporinlerin gelişigüzel kullanımı nedeniyle bunlara karşı dirençli mikroorganizmaların hızlı gelişiminde liderlik gibi konular geçmişte yaşadığımız tatsız deneyimlerden birkaçıdır. Halen antibiyotik kullanımı ve sezaryen ameliyatı yapılma sıklı̆̆1 yönünden ülkemizin OECD (Organisation for 
Co-operation and Economic Development) ülkeleri arasında ilk sırada yer aldığı bilinmektedir.

Ülkemiz sağlık sektöründe, başka ülkelerde geliştirilen teknoloji ve ilaçların, geliştiren ülkelerden daha hızlı ve yaygın kullanılmaya başlanması gibi bir özellik her dönemde öne çıkmaktadır. Bu hız ve yaygınlığın yenilikçi olmaya duyulan hevesten değil de bilgisizlikten, kolaycılıktan ve çıkar ilişkilerinden kaynaklandığı herkesin malumudur. Tüm gelişmiş ülkelerde tele-tıp ve evde bakım hizmetleri sayesinde tedavi edici hizmetler hastane dışına çıkmakta ve hastane boyutları küçülüp yatak sayıları azalmakta iken ülkemizde Şehir Hastaneleri ile tam tersi bir uygulama yoluna gidilmesi bunun en güncel örneğidir. Ünlü Roemer yasasına göre "ne kadar yatak, o kadar hasta” bulunması söz konusudur . Yani hastaneleri büyütmek, yatak sayılarını arttırmak, teknolojilerle donatmak, o altyapıyı kullanacak daha çok kişi bulmak, var etmek anlamına gelmektedir. Bunun da toplum sağlı̆̆ını geliştirmek yerine kaynakların verimsiz kullanımına neden olduğu çok eskiden beri bilinmektedir.

Yeni tıp teknolojilerinin bilinçsiz ve gelişigüzel kullanımı sadece tüketim sorunlarına değil pek çok etik soruna da neden olmaktadır.

\section{Yeni tıp teknolojilerine bağlı etik sorunlar}

Hepimizin şu ya da bu şekilde "iyi insan” olmak gibi bir saplantısı, tutkusu vardır. Gene hepimizin başkalarından daha üstün, daha farklı olmak gibi arzularımız bulunmaktadır. Bu özellikler bir yandan hekimleri ve kurumları hastalık tanı ve tedavisinde daha farklı, daha yeni yöntemler kullanmaya teşvik etmekte, bir yandan da yapılan işlerin doğruluğunu, etik yönünü sorgulamaya itmektedir. Aslında hiçbir tıbbi teknolojinin kendisinden kaynaklanan bir etik sorun yoktur. Etik sorunlar, teknolojiyi kullananların yeterliliği, becerisi ve doğru kullanımı ile ilgilidir.

Yeni gelişen tıbbi teknolojiler pek çok avantajlar sağlamanın yanı sıra sosyal ve etik sorunlara da neden olabil- mektedir. Yeni teknolojilere bağlı olarak ortaya çıkabilen başlıca sorunların hasta güvenliği, adalet ve bireysel normlarda değişme gibi konularda olduğu anlaşılmak$\operatorname{tad} \mathrm{r}^{5}$.

Hasta güvenliği sorunları: (Yararlı olma, Zarar vermeme) Her teknoloji onunla ilk kez karşılaşan ve ilk kez uygulayan kişi için yenidir. Yeni olanı tanımak, öğrenmek ve alışmak gerekir. Bunları kullanmanın kimler tarafından ve ne kadarlık bir sürede öğretileceği önemlidir. Yeni teknolojilerin bir an önce öğrenilip kullanılması konusunda hekimler üzerinde çok sayıda iç ve dış baskılar vardır. Ancak, özellikle el becerisi gerektiren cerrahi tekniklere hakim olabilmek için bir öğrenme eğrisi söz konusudur, yani süre gerekir. Nitekim yeni teknolojilerin uygulanmaya başladığı ilk dönemlerde hasta güvenliğini tehdit eden, ölümlere neden olan sonuçlarının görüldüğü bilinmektedir.

Örneğin, cerrahi alanda bir devrim niteliğinde olan ve günümüzde güvenli bir uygulama olan laparoskopik cerrahi, ilk uygulanmaya başladığı dönemde açık cerrahiye kıyasla daha fazla oranda komplikasyonlara neden olmuştur. Bugün de bu konuda yeterli bilgi-beceri ve deneyim sahibi olmayan hekimlerin komplikasyon oranları yüksek olabilmektedir. Beyine yapılan müdahalelerin özellikle çocuklarda, gelişme çağındaki kişilerde beyin ve merkezi sinir sistemini olumsuz etkileme riski vardır. Genetik müdahalelerin ise öngörülemeyen bazı sakıncalarının olabileceği bilinmektedir.

Yeni teknolojilerin ne derece güvenli olduğunu değerlendirmenin en doğru yolu onlara ilişkin bilimsel yayınlardır. Ancak, bu konuda da sorunlar vardır. İlk sorun yayınların genellikle taraflı olması, yani daha çok pozitif sonuçlara yer verilmesidir. İkinci sorun, yeni ilaç ve teknolojilerin güvenlik ve etkililik sonuçlarının ancak yaygın kullanımlarından sonra değerlendirilebilmesi, deneme öğrenme aşamasında yaşanan sorunların gözden kaçabilmesidir. Üçüncü sorun ise, yeni ilaçların kullanılmasına izin verilmeden önce gelişmiş ülkelerde randomize kon- 
trollü deneysel çalışmalar yapılma zorunluluğu olmasına karşın, bazı protez uygulamaları dışında yeni işlemler, teknikler ve yöntemler için hiç bir ülkede denetleyici bir mekanizmanın bulunmamasıdır. Örneğin, yeni cerrahi tekniklerin kullanılmaya başlanmasından yaklaşık 6-8 yıl sonra kontrollü deneysel çalışmaların yayınlandığı görülmektedir (koroner angioplasti ve laparaskopik kolesistektomi için süre bu şekilde hesaplanmıştır $\left.{ }^{6}\right)$.

$\mathrm{Bu}$ noktada yetişkin, aklı başında bireylerin kendilerine sunulan teknolojinin yarar-zarar dengesini bilmek kaydıyla karar vermeleri konusunda özgür olmaları gerektiği düşünülebilir ve liberal etikçiler açısından bu yaklaşım doğrudur. Ancak, bu yaklaşıma gelen itirazlar bedeni hakkında karar veren "ben"in kim olduğu konusunda toplanmaktadır. "Ben” ayrı bir kişilik olmayıp aslında beyin faaliyetlerinin bir ürünüdür ve beynin manipülasyonu, denetlenmesi, yönlendirilmesi pekala mümkün olduğundan bu konu daha başka etik tartışmaları gündeme getirmektedir.

\section{Adalet sorunları: (Adil olma)}

Yeryüzündeki kaynakların, toplumda var olan imkanların, adil, hakkaniyetli bir biçimde paylaşımı konusu insanlık tarihi kadar eski bir tartışma konusudur. Yeni teknolojilerden tüm insanların aynı ölçüde yararlanamaması halinde bunların sağlayacağı avantajların zaten var olan eşitsizliklere yenilerini katma gibi bir etkisinin olacağı ortadadır. Örneğin, gelişmiş teknolojilerle daha sağlıklı, daha da üstün insan haline gelme firsatını yakalayan bazı ayrıcalıklı kesimlerin diğer insanları dünya nimetlerinin paylaşımı açısından bir fazlalık olarak görmeye başlamaları mümkün olabilmektedir. ABD başkanı Trump’ı "bok çukuru ülkeler” nitelemesinde olduğu gibi bu tür adaletsizlik, eşitsizlik ve hakkaniyet sorunlarının bireyler arasında ve ülkeler arasında zaten var olduğu, bunlara neden olanlar tarafından bile rahatlıkla dile getirilen gerçeklerdir. "Bir kişinin bile sağlığına katkı sağlayacak ise bilimsel ve teknolojik gelişmeler desteklenmeli” düşüncesi kulağa hoş gelse de bunların getireceği avantajları elde eden insan- ların kardeşlik, dayanışma, eşitlik, paylaşma, adalet gibi değerleri savunmaya devam etmelerinin ne ölçüde mümkün olacağı konusu yanıtı zor bir sorudur.

Bireysel normların değişmesi ve toplumsal baskı sorunları: Genetik teknolojiler sayesinde yaşamın, nanoteknolojiler sayesinde maddelerin, nöroteknolojik gelişmeler sayesinde de beynin şekillendirilmesi mümkün hale gelmektedir. Bu şekillendirmeler yoluyla bireysel ve toplumsal normlar da değişmekte, yeni etik tartışmalar gündeme gelmektedir $^{3}$. Başka bir deyişle yeni tıp teknolojileri sayesinde hastalıkların tedavisi, bedensel ve zihinsel yetersizliklerin giderilmesi sağlanabildiği gibi, hiç bir sağlık sorunu olmayan insanların daha güzel, daha zeki, daha sağlıklı, daha uzun yaşayan bireyler haline getirilebilmesi de mümkün olabilmektedir. Bu durum ise "normal" kavramını değiştirmektedir. Nitekim günümüzde özellikle beden görünümü değiştirmek, zihinsel fonksiyonları arttırmak amacıyla tıbbi teknoloji yaygın şekilde kullanılmaktadır. Daha az kilolu, daha fit, daha keskin hafızalı, daha genç görünümlü olmak herkesin ortak arzusu haline gelmiş ve vücuttan yağ aldırma, bazı bölgelere dolgu maddeleri enjekte etme, kırışıklıkları giderme, botoks gibi tıbbi uygulamalar yaygınlaşmıştır. Başlangıçta ileri yaştaki kişiler için kullanılan bu teknolojiler giderek genç insanlar hatta çocuklar tarafından da kullanılmaya başlamıştır. Bu kullanımların büyük çoğunluğu tıbbi endikasyonlara bağlı olmaktan çok kozmetik amaçı kullanımlardır. Gelişen yeni teknolojiler bireysel ve toplumsal normları da değiştirmekte, günlük hayatı aşırı derecede tıplaştırmaktadır.

Öte yandan yeni teknolojik gelişmelerin özellikle insan sağlı̆̆ına yönelik olarak kaçınılmazlığını ve mutlaka desteklenmesini savunanlar da bulunmaktadır. Bu savunucuların görüşleri transhumanizm adlı yeni bir felsefi akımın ortaya çıkmasına neden olmuştur.

Transhumanizm sözcüğü ilk kez 1957 yılında kullanılmakla birlikte son 20-30 yılda gelişen bir felsefi akımdır. Buna göre gelişmiş teknolojilerin kullanımı ile insan zih- 
ninin ve fizyolojisinin şimdiki sınırlarını aşacak şekilde gelişmesi savunulmalı ve bu sayede insanoğlunun başka bir şeye dönüşmesi sağlanmalıdır?

$\mathrm{Bu}$ felsefeye göre özellikle genetik teknoloji, enformasyon teknolojisi, moleküler nanoteknoloji, yapay zeka gibi hızla gelişmekte olan yeni teknolojilerin etik kullanımı ile insan denilen varlığın, insan ötesi (post human) farklı bir varlığa dönüşmesi kaçınılmazdır. $\mathrm{Bu}$ nedenle bu gelişmelerin önündeki engellerin kaldırılması ve ortaya çıkacak yeni duruma hazırlanılması gerekmektedir. Yeni teknolojik gelişmeler tarihi anlamda ciddi bir dönüşümün ilk belirtileridir. Transhumanistlere göre bilim "Din ve politikanın başaramadıklarını başarma yolundadır. Örneğin, hastaları iyileştirmekte, açlık ve yoksulluğu çare üretmekte, zayıfların güçlü olmasına katkı sağlamaktadır. Belki günün birinde bize ölümsüzlük imkanını da sağlayacaktır” ${ }^{8}$.

Kulağa hoş gelse de tüm hastalıkların önlendiği, eskiyen doku ve organların yenileri ile değiştirilebildiği, kötü genetik kodların yeniden düzenlenebildiği, nesnelerin interneti sayesinde bedenimize ilişkin tüm olup bitenlerin kontrolümüz altında olduğu, beynimize takılan çiplerle yeni bilgileri yüklemenin, rahatsız edici eski anılardan arınmanın mümkün olduğu, siparişimize uygun zeka, güç ve yeteneklere sahip çocuklar üretmenin mümkün hale geldiği ve insan hayatının giderek uzadığı, hatta ölümsüzlüğün söz konusu olduğu bir çağa girildiğinde karşımıza ne tür insanlık sorunlarının çıkabileceği, üzerinde düşünülmesi gereken ciddi bir konudur.

Transhumanistlerin öngördüğü dünyanın, çok uzun bir gelecekte mümkün olabileceğini dikkate alıp, olası sorunları da bir yana koyarak günümüze döndüğümüzde, yeni teknolojilerin kullanımının gözetim ve denetiminden kimlerin sorumlu olması gerektiği, yaptırımların neler olacağı soruları yanıt bekleyen güncel sorulardır. Konu hastane etik kurullarına bırakıldığında eğer teknoloji ile ilgili yapılmış olumlu araştırmalar varsa kabul, yoksa reddedilmektedir. Kurumsal uygulamalarda sağlık yöneticisinin bu tür gözetim-denetim imkanı olmakla birlikte kendi muayenehanesinde çalışan bir hekim için bu tür bir imkan bulunmamaktadır. Hatalı uygulamaların yerel sağlık makamlarına, meslek örgütlerine yansıması ise çok ender olarak gerçekleşmektedir. Öte yandan tanı amaçlı yeni teknolojilerin kullanılmasına bağlı sorunları saptamak zaten çoğu kez mümkün olamamaktadır. Bu konuda katı bazı önlemlerin alınmasının ne derece mümkün ya da doğru olacağı da tartışmalıdır.

Tüm tartışmaların ışığında ortaya çıkan sonuca göre yeni teknolojilerin ahlaki biçimde kullanılma sorumluluğu öncelikle bunu kullanan kişilerdedir. Buna ek olarak, kurumsal uygulamalarda sağlık yöneticilerinin yapacağı etik düzenlemelerin de önemli rolü olmalıdır. 
Journal of BSHR 2019;3(2):54-60

HAYRAN. Yeni Tip Teknolojileri

\section{Kaynaklar}

1. 1-http://tdk.gov.tr erișim: 01.Mart.2019.

2. https://www.who.int/health-technology-assessment/about/healthtechnology/en/ erişim: 01.Mart.2019.

5. Wyatt J, Taylor P. Emerging Medical Technologies: Ethical issues. CMF file number 49, 2012.

3. Moor JH. Why we need better ethics for emerging technologies. Ethics and Information Technology 2005;7:111-119.

4. Roemer MI. Bed supply and hospital utilization: a natural experiment. Hospitals 1961;35:36-42

6. Iserson KV, Chiasson PM. The Ethics of Applying New Medical Technologies. Seminars in Laparoscopic Surgery, 2002; 9(4):222-229.

7. https://www.britannica.com/topic/transhumanism (erișim: 01.Mart.2019)

8. Young S. Designer Evolution: A Transhumanist Manifesto. New York: Prometheus Books. Press Release. 2006. 